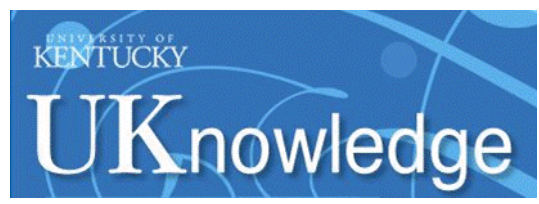

University of Kentucky

UKnowledge

\title{
7-2011
}

\section{Anesthetic Implications of Robotic Gynecologic Surgery}

\author{
J. Thomas McLarney \\ University of Kentucky, jtmcla00@email.uky.edu \\ Gregory L. Rose \\ University of Kentucky, glrose0@uky.edu
}

Follow this and additional works at: https://uknowledge.uky.edu/anesthesiology_facpub

Part of the Anesthesiology Commons

Right click to open a feedback form in a new tab to let us know how this document benefits you.

\section{Repository Citation}

McLarney, J. Thomas and Rose, Gregory L., "Anesthetic Implications of Robotic Gynecologic Surgery" (2011). Anesthesiology Faculty Publications. 3.

https://uknowledge.uky.edu/anesthesiology_facpub/3

This Article is brought to you for free and open access by the Anesthesiology at UKnowledge. It has been accepted for inclusion in Anesthesiology Faculty Publications by an authorized administrator of UKnowledge. For more information, please contact UKnowledge@lsv.uky.edu. 


\section{Anesthetic Implications of Robotic Gynecologic Surgery}

\section{Digital Object Identifier (DOI)}

http://dx.doi.org/10.4103/0974-1216.114077

\section{Notes/Citation Information}

Published in Journal of Gynecological Endoscopy and Surgery, v. 2, no. 2, p. 75-78.

(C) 2011 Journal of Gynecological Endoscopy and Surgery.

This is an open-access article distributed under the terms of the Creative Commons AttributionNoncommercial-Share Alike 3.0 Unported, which permits unrestricted use, distribution, and reproduction in any medium, provided the original work is properly cited. 


\title{
Anesthetic Implications of Robotic Gynecologic Surgery
}

\author{
J Thomas McLarney, Gregory L Rose \\ Department of Anesthesiology, University of Kentucky \\ College of Medicine, Lexington, Kentucky
}

\begin{abstract}
Surgery using robotic techniques is becoming more and more common. One of the specialties at the fore-front of robotic surgery has been gynecology, much like it was at the fore-front a generation ago in bringing laparoscopy into the operating room. New considerations have been noted and new techniques have been learned on both sides of the drape in order to ensure a successful outcome for the patient undergoing robotic gynecologic surgery. The purpose of this article is to bring, to light the concerns facing the anesthesiologist in regards to robotic procedures. We discuss the problems facing anesthesiologists, when a patient is experiencing both intraabdominal insufflation and steep Trendelenburg position, and also the intraoperative management of such a patient.
\end{abstract}

Key words: Anesthesia, physiology of laparoscopy, perioperative management, robotic surgery

\section{INTRODUCTION}

$S$ urgery using robotic techniques is becoming more and $S$ more common. One of the specialties at the fore-front of robotic surgery has been gynecology, much like it was at the fore-front a generation ago in bringing laparoscopy into the operating room. ${ }^{[1]}$ New considerations have been noted and new techniques have been learned on both sides of the drape in order to ensure a successful outcome for the patient undergoing robotic gynecologic surgery.

The reader has no doubt regarding the clinical indications and surgical implications of robotic surgery. The purpose of this article is to bring to light the concerns facing the anesthesiologist in regards to robotic procedures.

\section{ANESTHETIC CONCERNS OF INSUFFLATION AND STEEP TRENDELENBERG POSITION}

Anesthesiologists and surgeons both are familiar with the physiologic changes that accompany the establishment of a pneumoperitoneum. The subsequent, increased intra-abdominal pressure from insufflations causes increases in mean arterial pressure, systemic vascular resistance,

\section{Address for correspondence: \\ Dr. Gregory Rose, \\ 1240 Todds Station, Lexington-USA. \\ E-mail: glrose0@email.uky.edu}

and central venous pressure, along with decreased venous return ${ }^{[1-4]}$ and heart rate can also increase. ${ }^{[1,2]}$ The renin-angiotensin system is activated by the increase in intra-abdominal pressure, aiding in raising blood pressure, systemic vascular resistance, and increasing intravascular volume by decreasing urine output. ${ }^{[2]} \mathrm{A}$ decrease in splanchnic blood flow (including hepatic blood flow) secondary to the pneumoperitoneum will also augment intravascular volume and blood pressure. ${ }^{[5]}$ Absorption of carbon dioxide from the peritoneal cavity into the blood stream will also increase blood pressure. ${ }^{[2,5]}$ Intracerebral, intraocular, and peak airway pressures all increase as a result of increased intra-abdominal pressure. ${ }^{[2,6]}$ At intra-abdominal pressures over $15 \mathrm{mmHg}$, decreases in mean arterial pressure can be noted due to compression of the inferior vena cava, thereby, decreasing venous return, preload, and cardiac output. ${ }^{[5,6]}$

One of the main concerns during an anesthetic for laparoscopy is proper ventilation. Pneumoperitoneum decreases total lung capacity (TLC), and functional residual capacity (FRC) is reduced. ${ }^{[2,5,6]}$ Because of these

Access this article online

Quick Response Code:

Website:

www.gynecendoscopy.org 
changes in lung volumes, various ventilation problems can arise. The decreased TLC and FRC mean that, there will be areas of the lungs where there is perfusion but no ventilation, which will cause both decreased oxygenation, but also decreased exchange of carbon dioxide. Decreased FRC and increased closing capacity lead to atelectasis. Peak airway pressures increase, ${ }^{[7]}$ which raises the risk of barotrauma (pneumothorax) and decreases the ability of the anesthesiologist to adequately ventilate the patient.

Because of the increase in $\mathrm{V} / \mathrm{Q}$ mismatch, decrease in lung volumes, and the possible need to decrease tidal volumes in light of high peak airway pressures, ${ }^{[7]}$ it may be difficult to control the partial pressure of carbon dioxide in the patient's bloodstream $\left(\mathrm{PaCO}_{2}\right) \cdot{ }^{[2,6,7]}$ This is all the more an issue since, the patient is being given extraneous carbon dioxide via the pneumoperitoneum in addition to the patient's own production of carbon dioxide. Respiratory acidosis, with subsequent sympathetic stimulation, can cause myocardial depression and increases in cerebral blood flow and intracranial pressure. ${ }^{[6]}$ A large amount of carbon dioxide may persist in the patient even upon emergence from anesthesia, necessitating post-operative ventilation to correct the hypercarbia. Any subcutaneous insufflation of carbon dioxide will also worsen the hypercarbia situation post-operatively. ${ }^{[7]}$

Other potential complications of pneumoperitoneuminclude venous gas embolism, ${ }^{[2,5,6]}$ pneumothorax (not secondary to positive pressure ventilation), pneumomediastinum ${ }^{\mathrm{m}}$, and pneumocardium. ${ }^{[1]}$

In steep Trendelenburg position $\left(25^{\circ}-40^{\circ}\right)$ with pneumoperitoneum, all the above still occur, but their effects can be magnified. In addition to magnifying cardiovascular problems, the patient will be even more difficult to ventilate. Badaway, et al., reported an incidence of intraoperative hypercapnia $\left(\mathrm{ETCO}_{2}>45 \mathrm{mmHg}\right)$ in $18 \%$ of their series of 133 patients undergoing robotic hysterectomy. Their incidence of significant intraoperative hypoxemia $\left(\mathrm{SpO}_{2}<90 \%\right)$ was less than $4 \%$. Only 7 of their 133 patients' required post-operative ventilation, with length of ventilation ranging from $1 \mathrm{~h}$ to $5 \mathrm{~h}$. Reasons given for the need for post-operative ventilation in those five patients included hypercapnia, hypothermia, inadequate reversal of muscle relaxants, and relative excessive narcotic administration. None of their patients required reintubation. ${ }^{[3]}$

Edema of the face can be seen, along with conjunctival edema. Corneal abrasions are associated with gynecological laparoscopy ${ }^{[8]}$ This edema can push the patient's upper and lower eyelids apart, causing desiccation and abrasion of the cornea, even when the eyes are taped closed. A horizontal line across the cornea is seen on ophthalmic examination post-operatively. Steep Trendelenburg with increased intraabdominal pressure from insufflation raises intragastric pressure, and passive aspiration of stomach fluid into patients' eyes has been reported.

Intraocular pressure (IOP) rises during steep Trendelenburg position to levels that are similar to those of untreated glaucoma patients in a study of IOP changes in robotic prostatectomies. The average rise in IOP was $13 \mathrm{mmHg}$ from preoperative baseline. IOP increased with length of procedure and end tidal carbon dioxide levels. ${ }^{\left[{ }^{[9}\right.}$ Therefore, patients with glaucoma may be unsuitable for robotic procedures if steep Trendelenburg position is required.

Steep Trendelenburg position, with the resultant increases in central venous pressure, intracranial pressure, and IOP over a long period of time can possibly result in posterior ischemic optic neuropathy, a catastrophic complication with permanent blindness of the affected eye. This complication has been reported twice, after a robotic prostatectomy and a minimally invasive laparoscopic prostatectomy, both of which were prolonged cases in steep Trendelenburg. ${ }^{[10]}$

Furthermore, of concern to the anesthesiologist is the possibility of edema of the supraglottic airway structures, namely the vocal cords, arytenoids, and epiglottis. ${ }^{[4]}$ In such a situation, the patient will be stridorous or be unable to move air on their own once the endotracheal tube is removed, requiring emergent reintubation in the post-anesthesia care unit, and the edema can make reintubation more difficult than intubation on pre-operative induction. In the Badaway study, he stated instances of laryngeal edema were rare, but no numbers of patients affected were given. ${ }^{[3]}$

The lower extremities may be hypo perfused in steep Trendelenburg and cases of post-operative rhabdomyolosis have been seen. ${ }^{[1]]}$ A situation such as this would be made worse by overly-tight table straps, and improper positioning of leg holders (which can also cause peroneal and femoral nerve damage). ${ }^{[2]}$ Femoral vein blood flow is decreased by pneumoperitoneum. ${ }^{[6]} \mathrm{A}$ brachial plexus injury from shoulder braces has been reported from robotic prostatectomy. ${ }^{[4]}$

\section{INTRAOPERATIVE ANESTHETIC MANAGEMENT}

Proper patient selection is of course very important and may necessitate frank discussion between the anesthesiologist and gynecologist pre-operatively, with 
the hope that the discussion occurs before the patient gets to the pre-operative holding room. Any patient with significant cardiovascular or pulmonary disease or with morbid obesity should be seen by the anesthesiologist well in advance of the scheduled operative date. Those with severe cardiac disease may tolerate an open procedure better than a robotic procedure because of the increased operative time coupled with the adverse physiologic effects of insufflation and steep positioning that are associated with robotic laparoscopic procedures.

While, regional anesthesia for laparoscopic procedures has been described, these cases did not involve the prolonged time and steep positioning needed for robotic hysterectomy. A general anesthetic is required for obvious reasons, including the fact that the airway is relatively inaccessible when the robot is docked, the work of breathing in steep Trendelenburg would be so much as to cause respiratory distress quickly, especially in the presence of a pneumoperitoneum.

Most anesthesiologists would maintain muscle relaxation during the procedure, for several reasons. One reason is the potential for diaphragmatic activity due to hypercarbia, desire for akinesis, increased pulmonary compliance, and increased abdominal wall compliance. Even though some studies have downplayed the beneficial effects of the use of muscle relaxant drug administration during laparoscopy, ${ }^{[2]}$ stating there is no significant difference in intraperitoneal compliance, the use of such drugs for any type laparoscopy is commonplace.

It has been our experience that those patients with pulmonary disease or morbid obesity can tolerate robotic procedures if ventilation is not too problematic. An arterial line would be of benefit to closely monitor the patient's arterial blood gas to more easily recognize hypercarbia. End-tidal carbon dioxide values can be significantly less than actual $\mathrm{PaCO}_{2}$ for several reasons, such as $\mathrm{V} / \mathrm{Q}$ mismatch.

Non-invasive blood pressure monitoring is acceptable in many cases if the surgeon feels blood loss will not be severe and the anesthesiologist is comfortable with only non-invasive monitoring. Blood pressure measurements with non-invasive blood pressure cuffs should not be done on the patient's lower extremities, because the blood pressure value in steep Trendelenburg will underestimate the blood pressure in more central areas, due to the hydrostatic difference (one inch of vertical distance is approximately equal to two $\mathrm{mmHg}) \cdot{ }^{[2]}$
A problem with robotic procedures is the difficulty in accessing the patient if the anesthesiologist needs to because not only are the arms tucked, but the robotic apparatus impairs our ability to get to the patient. A second intravenous line is good to have in case the original one is lost or infiltrates.

The robot also interferes with access to the patient's airway and chest. The endotracheal tube should be securely taped to the patient, allowing no migration once the tube is situated. The anesthesiologist also needs to remember that insufflation and Trendelenburg can cause the diaphragm, lungs, and carina to shift cranially, so an endobronchial intubation can occur after positioning and the pneumoperitoneum is established. ${ }^{[13]}$

The morbidly obese patient presents specific problems. While the concern about ventilation is obvious, positioning may be a problem as well. Intravenous access and non-invasive blood pressure measurement may also present problems.

While many anesthesiologists do not use ophthalmic ointment for most cases, we feel its use is of importance with robotic procedures. The potential of corneal desiccation from the eyelids separating secondary to conjunctival edema is lessened with the ointment, which acts as a shield protecting the cornea. An orogastric tube is necessary for gastric decompression not only to aid surgical exposure, but to decrease the chance of passive aspiration of stomach acid onto the face and possibly into the eyes. Again, ophthalmic ointment may be beneficial in helping to protect the eyes from this circumstance.

If airway edema is suspected, based on the degree of facial, conjunctival or tongue edema, several steps can be taken. One would be to leave the patient intubated, sedated, and ventilated until facial edema has decreased, assuming that airway edema has subsided similarly. A direct laryngoscopy before emergence from anesthesia can be performed to look for edema of the airway, especially, edema of the epiglottis and soft tissue of the pharynx. A "leak test" of the airway can be accomplished with a spontaneously breathing patient by deflating the endotracheal tube cuff to ascertain if there is enough room around the tube at the glottis for air to pass, as an indicator of glottis edema. Finally, an endotracheal tube changer, bougie stylet, or similar device can be placed inside the endotracheal tube at extubation. If reintubation is needed, the tube can rapidly be placed over the stylet. Most patients will tolerate leaving such a stylet in their trachea during the immediate post-extubation period. There should be a low threshold of reintubation on a patient who 
is stridorous and struggling to breathe after a prolonged procedure in steep Trendelenburg.

\section{CONCLUSION}

Robotic surgery is common place in gynecology now, and will have no doubt in spreading to other surgical specialties much like laparoscopy did in the past. Both anesthesiology and gynecology need to understand the other specialty's concerns regarding this new technique. In doing so, patient outcome and satisfaction will continue to increase.

\section{REFERENCES}

1. Gerges FJ, Kanazi GE, Jabbour-Khoury SI. Anesthesia for laparoscopy: A review. J Clin Anesth 2006;18:67-78.

2. Olympio MA. Anesthetic considerations for robotic urologic surgery. In: Hemel AK, Menon M, editors. Robotics in Genitourinary Surgery. London: Springer-Verlag Limited; 2011. p. 79-95.

3. Badaway M, Beique F, Al-Halal H, Azar T, Akkour K. Anesthesia considerations for robotic surgery in gynecologic oncology. J Robot Surg 2011;5:235-9.

4. Phong SV, Koh LK. Anaesthesia for robotic-assisted radical prostatectomy: Considerations for laparoscopy in the Trendelenburg position. Anaesth Intensive Care 2007;35:281-5.

5. Gutt CN, Oniu T, Mehrabi A, Schemmer P, Kashfi A, Kraus T, et al. Circulatory and respiratory complications of carbon dioxide insufflation.
Dig Surg 2004:21:95-105.

6. O’Malley C, Cunningham AJ. Physiologic changes during laparoscopy. Anesthesiol Clin North America 2001;19:1-19.

7. Rauh R, Hemmerling TM, Rist M, Jacobi KE. Influence of pneumoperitoneum and patient positioning on respiratory system compliance. J Clin Anesth 2001;13:361-5.

8. Kim K, Kim HJ, No JH, Kim TW, Kim YB, Suh CS. Increased risk for post-operative corneal injuries in patients who undergo laparoscopic gynecologic surgery. Acta Anaesthesiol Scand 2012;56:504-6.

9. Awad H, Santilli S, Ohr M, Roth A, Yan W, Fernandez S, et al. The effects of steep trendelenburg positioning on intraocular pressure during robotic radical prostatectomy. Anesth Analg 2009;109:473-8.

10. Weber ED, Colyer MH, Lesser RL, Subramanian PS. Posterior ischemic optic neuropathy after minimally invasive prostatectomy. J Neuroophthalmol 2007:27:285-7.

11. Galyon SW, Richards KA, Pettus JA, Bodin SG. Three-limb compartment syndrome and rhabdomyolysis after robotic cystoprostatectomy. J Clin Anesth 2011;23:75-8.

12. Chassard D, Berrada K, Tournadre J, Boulétreau P. The effects of neuromuscular block on peak airway pressure and abdominal elastance during pneumoperitoneum. Anesth Analg 1996;82:525-7.

13. Lobato EB, Paige GB, Brown MM, Bennett B, Davis JD. Pneumoperitoneum as a risk factor for endobronchial intubation during laparoscopic gynecologic surgery. Anesth Analg 1998;86:301-3. 